\title{
THE COORDINATION OF THE ACTIVITIES OF THE LAW ENFORCEMENT AGENCIES FOR THE PREVENTION AND DETECTION OF CRIMES COMMITTED BY MINORS
}

\author{
Pyotr P. Muraev \\ Volgograd State University, Volgograd, Russian Federation
}

Roman P. Muraev

Department of the Ministry of Internal Affairs of Russia in Volgograd, Volgograd, Russian Federation

\author{
Olga E. Andryushchenko
}

Volgograd State University, Volgograd, Russian Federation

Introduction: the crime rate of the minor category of the population is currently not decreasing, as evidenced by the statistical data indicated in the paper. The increase in the level of its public danger exacerbates the criminal situation in the Russian Federation, including the Volgograd region. To combat this destructive phenomenon, it is necessary to consolidate the efforts of all the law enforcement agencies by coordinating their activities. In this regard, the development and introduction of effective prevention measures among minors are relevant. The purpose of the paper: to identify the promising areas for improving the efficiency of the law enforcement management. Objectives: to describe the concept of "coordination", the essence and content of the coordination activities of the law enforcement agencies to combat juvenile delinquency; to analyze the legislative framework for the coordination of the law enforcement agencies to combat juvenile delinquency and to identify practical problems in its implementation; to propose the main directions for improving the regulatory and legal support of the coordination activities of the law enforcement agencies. Methods: the authors used the general scientific, systemic, and institutional research methods, as well as the methods of legal statistics, which made it possible to solve the tasks set for the research team. Results: the problems in the youth environment are characterized, the promising areas of prevention of juvenile delinquency are identified, and the results of the fight against youth crime in the city of Volgograd, the Volgograd Region and the country as a whole are shown using the methods of legal statistics. Conclusions: in order to improve the coordination of the law enforcement system for the prevention of uvenile delinquency, the authors of the paper suggest that, on a coordinated basis, with the participation of prevention subjects, they seek the solutions to the problems of youth employment, organize events together with the operational units in order to identify criminal groups, separate these groups; regularly conduct preventive work with their relatives.

Key words: coordination, optimization, interaction, law enforcement agencies, crime control, juvenile delinquency, control.

Citation. Muraev P.P., Muraev R.P., Andryushchenko O.E. The Coordination of the Activities of the Law Enforcement Agencies for the Prevention and Detection of Crimes Committed by Minors. Legal Concept $=$ Pravovaya paradigma, 2021, vol. 20, no. 2, pp. 33-40. (in Russian). DOI: https://doi.org/10.15688/lc.jvolsu.2021.2.5

КООРДИНАЦИЯ ДЕЯТЕЛЬНОСТИ ПРАВООХРАНИТЕЛЬНЫХ ОРГАНОВ ПО ПРОФИЛАКТИКЕ И РАСКРЫТИЮ ПРЕСТУПЛЕНИЙ, СОВЕРШАЕМЫХ НЕСОВЕРШЕННОЛЕТНИМИ

\section{Петр Петрович Мураев}

Волгоградский государственный университет, г. Волгоград, Российская Федерация 


\title{
Роман Петрович Мураев
}

\author{
Управление МВД России по г. Волгограду, г. Волгоград, Российская Федерация
}

\section{Ольга Евгеньевна Андрющенко}

Волгоградский государственный университет, г. Волгоград, Российская Федерация

\begin{abstract}
Введение: преступность несовершеннолетней категории населения в настоящее время не уменьшается, о чем свидетельствуют статистические данные, указанные в статье. Повышение уровня ее общественной опасности обостряет криминогенную ситуацию в Российской Федерации, включая и Волгоградскую область. Для борьбы с этим деструктивным явлением необходима консолидация усилий всех правоохранительных органов посредством координации их деятельности. В связи с этим актуальна проработка и введение действенных мер профилактики среди несовершеннолетних. Цель статьи: выявить перспективные направления повышения эффективности управления правоохранительными органами. Задачи: охарактеризовать понятие «координация», сущность и содержание координации деятельности правоохранительных органов по борьбе с несовершеннолетней преступностью; проанализировать законодательные основы координации правоохранительных органов по борьбе с несовершеннолетней преступностью и выявить практические проблемы при ее осуществлении; предложить основные направления по совершенствованию нормативного правового обеспечения координационной деятельности правоохранительных органов. Методы: авторами использованы общенаучные, системный, институциональный методы исследования, а также методы правовой статистики, позволившие решить поставленные перед исследовательским коллективом задачи. Результаты: охарактеризованы проблемы в молодежной среде, выявлены перспективные направления профилактики преступности несовершеннолетних, а также с помощью методов правовой статистики показаны результаты борьбы с молодежной преступностью в г. Волгограде, Волгоградской области и по стране в целом. Выводы: в целях повышения координационной деятельности правоохранительной системы профилактики несовершеннолетней преступности авторы статьи предлагают на координационной основе при участии субъектов профилактики искать решение проблем занятости молодежи, организовывать мероприятия совместно с оперативными подразделениями для выявления преступных группировок, разобщения этих группировок; регулярно проводить профилактическую работу с их родственниками.
\end{abstract}

Ключевые слова: координация, оптимизация, взаимодействие, правоохранительные органы, борьба с преступностью, преступность среди несовершеннолетних, контроль.

Цитирование. Мураев П. П., Мураев Р. П., Андрющенко О. Е. Координация деятельности правоохранительных органов по профилактике и раскрытию преступлений, совершаемых несовершеннолетними // Legal Concept = Правовая парадигма. -2021 . - T. 20, № 2. - C. 33-40. - DOI: https://doi.org/10.15688/lc.jvolsu.2021.2.5

\section{Введение}

Состояние преступности Российской Федерации на протяжении многих лет беспокоит институты государства и гражданского общества. Преступность, являясь одним из основных деструктивных явлений, представляет серьезную угрозу различным слоям российского социума [2, с. 148]. Ситуация усугубляется и ростом криминального насилия, интенсивной криминогенности среди несовершеннолетних.

Преступность лиц несовершеннолетнего возраста как на территории Волгоградской области, так и в стране в целом - одна из актуальных проблем [1, с. 126]. В частности, в Волгоградской области многие детские учреждения перестали функционировать, а по- мещения, где они базировались ранее, были сданы в аренду коммерческим структурам. Стоит заметить, что идет процесс разрушения системы оздоровления и летней занятости. Все эти проблемы усугубляются на фоне увеличения случаев домашнего быта на общем фоне бедности и постоянной нужды, моральной и социальной деградации, происходящей в семьях, что, несомненно, приводит к очень печальным последствиям - созданию криминогенной обстановки.

Так, согласно статистическим данным ИЦ ГУ МВД по Волгоградской области, за 12 месяцев 2020 г. количество преступлений, совершенных несовершеннолетними, увеличилось по сравнению с прошлым годом и составило 873 преступления (АППГ - 856) $(+17,+2 \%)$. 
Количество преступлений, совершенных несовершеннолетними без участия в составе группы, 469 (АППГ - 529). Количество преступлений, совершенных несовершеннолетними без участия в составе группы, зарегистрировано 404 (АППГ - 327). Преступными группами, в состав которых входили только несовершеннолетние, совершено 216 преступлений (АППГ 165), группами в соучастии с лицами, достигшими возраста совершеннолетия, - 182 (АППГ - 162).

Из указанного количества зарегистрированных преступлений ранее судимыми несовершеннолетними совершено 159 преступлений (АППГ - 131) (табл. 1).

К сожалению, можно заключить, что деятельность правоохранительных органов по борьбе с преступностью лиц несовершеннолетнего возраста вызывает ряд вопросов по ее эффективности. В.М. Шинкарук и П.П. Фантров справедливо полагают, что этому способствует ряд факторов, основными среди которых являются: кризисное состояние отечественной экономики, психологическая склонность несовершеннолетних к совершению преступлений, отчуждение несовершеннолетних от общества, их бесцельное времяпрепровождение, отсутствие нормальных условий существования у некоторых подростков и пр. [10, с. 113].

\section{Особенности координации деятельности правоохранительных органов с преступностью среди несовершеннолетних}

Важную роль играет профилактика преступлений среди несовершеннолетних [8, c. 23]. Приходится признать, что она довольно слабая. Необходимы определенные социальные, правовые, педагогические и иные меры, которые будут направлены на выявление и недопущение причин и условий преступности. Это касается не только правоохранительных органов, но и других субъектов. Еще одной из немаловажных причин является плохая организация работы с молодежью [9, c. 264]. Совместно должны работать школа, родители и правоохранительные органы. Только при их слаженной деятельности формируется единый подход к проблеме профилактики преступлений.

Координация деятельности правоохранительных органов является важным условием борьбы с преступностью лиц несовершеннолетнего возраста. Именно этому направлению деятельности принадлежит огромная роль в консолидации усилий правоохранительных структур [11, с. 181], которая способствует значительному повышения результативности действий по борьбе с преступностью несовершеннолетних. Следует выделить основные направления деятельности правоохранительных органов по борьбе с преступностью, в том числе и среди несовершеннолетних, по которым она должна проводиться. Они регламентируются Положением о координации деятельности правоохранительных органов по борьбе с преступностью, утвержденным Указом Президента Российской Федерации от 18 апреля 1996 г. № 567 (ред. от 31.12.2019). В соответствии с данным правовым актом основными формами координации выступают следующие: «...проведение координационных совещаний; обмен информацией по вопросам борьбы с преступностью; совместные выезды в регионы для проведения слаженных действий, проверок и оказания помощи местным правоохранительным органам по борьбе с преступностью; создание следственно-оперативных групп для расследования определенных преступлений; проведение общих целевых

Таблица 1

Преступления, совершенные несовершеннолетними, по основным видам

\begin{tabular}{|c|c|}
\hline Статья УК РФ & Количество преступлений (АППГ) \\
\hline 105 & $1 / 0$ \\
\hline 111 & $9 / 8$ \\
\hline 158 & $440 / 541$ \\
\hline 161 & $132 / 118$ \\
\hline 162 & $21 / 12$ \\
\hline 166 & $106 / 46$ \\
\hline
\end{tabular}


мероприятий для выявления и предотвращения преступлений, а также устранения причин и условий, способствующих их совершению; взаимное применение возможностей правоохранительных органов для повышения квалификации работников, проведение совместных семинаров, конференций» [6].

Одним из организационных способов достижения координации правоохранительных органов в борьбе с несовершеннолетней преступностью является «...принятие согласованных мер по выявлению, предупреждению, установлению лиц, совершивших преступления, и гарантированному обеспечению их уголовного преследования» [5, с. 149].

Задачи координации деятельности силовых структур по борьбе с несовершеннолетней преступностью более конкретны по своему содержанию, а также рассчитаны на определенный срок (период). Полагаем, к приоритетным задачам координационной деятельности правоохранительных органов по борьбе с этим видом преступности необходимо отнести:

- разработку и реализацию силовыми структурами скоординированных действий в целях своевременного выявления, пресечения и предупреждения преступлений несовершеннолетних, раскрытие и расследование преступлений, совершенных несовершеннолетними, принятие мер в целях устранения причин и условий, порождающих совершение ими преступлений;

- согласование необходимых усилий в контексте осуществления деятельности силовых структур по борьбе с преступностью лиц несовершеннолетнего возраста;

- недопущение повторения вследствие рационального разграничения направлений деятельности правоохранительных органов по противодействию преступности несовершеннолетних.

У судов возникают вопросы при применении законодательства, общепризнанных принципов и норм международного права. Согласно Постановлению Пленума Верховного Суда Российской Федерации от 1 февраля 2011 г., «...правосудие в отношении несовершеннолетних правонарушителей должно быть направлено на то, чтобы применяемые к ним меры воздействия обеспечивали максимально индивидуальный подход к исследованию обстоятельств совершенного деяния и были соизмеримы как с особенностями их личности, так и с обстоятельствами совершенного деяния, способствовали предупреждению противозаконных действий и преступлений несовершеннолетних» [7].

В целях координации внутриведомственного взаимодействия в сфере профилактики правонарушений и преступлений несовершеннолетних в составе рабочей группы сотрудниками криминальной полиции осуществлены выезды в территориальные органы (ОМВД России по Палласовскому, Котельниковскому, Светлоярскому, Камышинскому, Ольховскому районам).

За 12 месяцев 2020 г. на территории Волгоградской области в целом всеми службами выявлено 31 преступление, предусмотренное ст. 150 УК РФ, из них сотрудниками криминальной полиции - 18 (АППГ - 17); раскрыто - 30, сотрудниками криминальной полиции - 12 (АППГ - 8).

В соответствии с п. 6 приказа МВД России от 1 сентября 2012 г. № 839 «О совершенствовании деятельности ЦВСНП» организация оперативно-розыскной работы в ЦВСНП по предупреждению, выявлению и раскрытию преступлений, совершаемых несовершеннолетними и в отношении них, возлагается на подразделения криминальной полиции территориальных органов ГУ МВД России на региональном и районном уровнях.

Необходимо перерабатывать и направлять по необходимости в территориальные подразделения ГУ МВД России по Волгоградской области график посещения ЦВСНП сотрудниками подразделений, закрепленными за направлением по выявлению и раскрытию преступлений, совершенных несовершеннолетними. Сведения по содержащимся несовершеннолетним предоставляются сотрудниками ЦВСНП ГУ в ГУ МВД России по Волгоградской области еженедельно, на основании чего в указанный график могут вноситься корректировки в зависимости от наличия несовершеннолетних в ЦВСНП ГУ и по согласованию с ЦВСНП ГУ.

Необходимо внести коррективы в общий план ГУ МВД по Волгоградской области по предупреждению преступлений, который состоит из трех форм: 
- социальная или общая профилактика, включающая в себя профилактические мероприятия на качественно-количественные характеристики преступности лиц несовершеннолетнего возраста;

- собственно криминологическая профилактика, предупреждение видов и форм преступного поведения несовершеннолетних, пресечение преступлений отдельными социальными группами;

- индивидуальная криминологическая профилактика.

Общая профилактика преступлений несовершеннолетних, реализуемая усилиями правоохранительных органов на территории Волгоградской области, должна включать в себя деятельность, сущность которой заключается в разрешении разногласий как в социальной жизни, так и нравственно-духовной сфере. Субъектами здесь должны еще выступать органы государственной власти, общественные объединения, для которых функция предупреждения преступности лиц несовершеннолетнего возраста не является основной либо профессиональной [12, с. 406].

Еще одной формой координации деятельности правоохранительных органов по борьбе с преступностью среди несовершеннолетних, которую необходимо внедрять в правоохранительную практику, является криминологическая профилактика преступлений, представляющая собой деятельность на скоординированной основе, специально нацеленную на недопущение и предупреждение преступлений несовершеннолетней молодежи. Ее разновидностями являются уголовно-правовая профилактика и специальная криминологическая профилактика. Так, уголовно-правовую профилактику следует охарактеризовать как «...систему мер предупреждения преступлений, опирающуюся на возможности частной и общей превенции, основанную на применении или угрозе применения уголовного наказания, реализуемых в связи и по поводу совершения или подготовки преступлений» [4, с. 45]. Уголовно-правовая профилактика направлена на недопущение рецидива или повторного совершения несовершеннолетним преступления. Специальная криминологическая профилактика, в свою очередь, представляет вид деятельности, которая направлена специально на недопущение несовершеннолетней преступности. Правоохранительными органами она осуществляется не только в результате воздействия на причины и условия совершения несовершеннолетними преступлений, но и в отношении тех лиц несовершеннолетнего возраста, которых необходимо удержать от совершения ими преступлений.

Индивидуальная профилактика преступлений среди несовершеннолетних включает в себя совокупность мер по выявлению и положительному воздействию на лиц несовершеннолетнего возраста, которые могут реально совершить преступление исходя из их поведения и образа жизни [3, с. 105]. В контексте данной проблематики целесообразно выделить основания применения мер индивидуального предупреждения преступлений:

- неоднократное совершение несовершеннолетним административных правонарушений с увеличением степени их общественной опасности, свидетельствующее о возможности совершения им преступления;

- антиобщественное поведение, образ жизни лица;

- личностные качества человека, характеризующие деформацию его поведения;

- неблагополучные условия в семье, бытовом окружении;

- определенные периоды неблагоприятной жизненной ситуации, имеющие криминальный характер и существующие довольно продолжительное время.

\section{Заключение}

Таким образом, профилактика преступлений несовершеннолетних, реализуемая усилиями правоохранительных органов на территории Российской Федерации в целом и Волгоградской области, в частности, должна включать в себя деятельность, сущность которой заключается в разрешении разногласий, как в социальной жизни, так и в нравственнодуховной сфере.

Процесс изучения личности, индивидуальное прогнозирование - задачи достаточно сложные, и решаются они в совокупности внутренних и внешних факторов. Чем точнее прогноз и представленная информация о лице, разработка и реализация силовыми структурами скоор- 
динированных действий в целях своевременного выявления, предупреждения и пресечения преступлений несовершеннолетних, тем эффективнее действенные меры пресечения преступления среди несовершеннолетних. Полностью искоренить несовершеннолетнюю преступность при больших масштабах довольно сложно, но снизить ее рост - вполне реальная задача, значит, с преступностью можно бороться.

\section{СПИСОК ЛИТЕРАТУРЫ}

1. Гуляихин, В. Н. Концептуальное измерение проблем совместной деятельности институтов государства и гражданского общества по обеспечению национальной безопасности РФ / В. Н. Гуляихин, П. П. Фантров // Вестник Волгоградского государственного университета. Серия 4 , История. Регионоведение. Международные отношения. 2016. -№ 3. - С. 122-131.

2. Гуляихин, В. Н. Традиционные духовнонравственные ценности в ассоциациях учащейся молодежи Волгоградской области / В. Н. Гуляихин, О. Е. Андрющенко, П. П. Фантров // Социологические исследования. - 2018. - № 11. - С. 146-151.

3. Мураев, П. П. Виды и задачи зарубежных и отечественных подразделений ОВД по организации обеспечения общественного порядка, их взаимодействие в предупреждении преступлений / П. П. Мураев // Вестник Волгоградской академии МВД России. - 2009. - № 3. - С. 102-109.

4. Мураев, П. П. Особенности профилактики экстремизма в молодежной среде / П. П. Мураев, Д. Н. Яковлев, В. В. Шалимова // Legal Concept $=$ Правовая парадигма. - 2020. - № 2. - С. 43-49. DOI: https://doi.org/10.15688/lc.jvolsu.2020.2.6.

5. Мураев, П. П. Правовая основа деятельности оперативных подразделений органов внутренних дел по выявлению, профилактике и раскрытию преступлений, совершаемых организованными преступными формированиями / П. П. Мураев, Н. А. Соловьева // Вестник Воронежского института МВД России. - 2018. - № 3. - С. 147-152.

6. О координации деятельности правоохранительных органов по борьбе с преступностью : указ Президента РФ от 18 апреля 1996 г. № 567 (ред. от 31.12.2019). - Доступ из справ.-правовой системы «КонсультантПлюс».

7. О судебной практике применения законодательства, регламентирующего особенности уголовной ответственности и наказания несовершеннолетних : постановление Пленума Верховного Суда Российской Федерации от 1 февраля 2011 года // Рос. газ. - 2011. - № 29 (5405).
8. Соловьева, Н. А. Интеграция государства и гражданского общества в сфере профилактики молодежного экстремизма в контексте правовой социализации / Н. А. Соловьева, П. П. Фантров // Legal Concept $=$ Правовая парадигма. -2020 . - № 2. - C. $21-$ 26. - DOI: https://doi.org/10.15688/lc.jvolsu.2020.2.3.

9. Фантров, П. П. Национальная модель политической социализации молодежи и национальная безопасность России / П. П. Фантров // Национальные интересы: приоритеты и безопасность. - 2017. - № 2. - С. 261-269.

10. Шинкарук, В. М. Координация деятельности правоохранительных органов и конструктивных ассоциаций граждан в контексте профилактики молодежного экстремизма / В. М. Шинкарук, П. П. Фантров // Вопросы российского и международного права. - 2020. - № 7А. - С. 111-120.

11. Шинкарук, В.М.Противодействие экстремизму в молодежной среде: роль прокурорского надзора за исполнением законодательства в данной сфере / В. М. Шинкарук, П. П. Фантров, Н. А. Соловьева // Вестник Волгоградской академии МВД России. -2020 . - № 4. - С. 178-188.

12. Шинкарук, В. М. Сетевые технологии взаимодействия силовых и конструктивных общественных структур в контексте профилактики молодежного экстремизма / В. М. Шинкарук, П. П. Фантров // Новые импульсы развития: вопросы научных исследований : сб. ст. Междунар. науч.-практ. конф. Саратов : КДУ, 2020. - С. 404-409.

\section{REFERENCES}

1. Gulyaikhin V.N., Fantrov P.P. Konceptual'noe izmerenie problem sovmestnoj deyatel'nosti institutov gosudarstva i grazhdanskogo obshchestva po obespecheniyu nacional'noj bezopasnosti RF [Conceptual Dimension of the Problems of Joint Activities of State and Civil Society Institutions to Ensure the National Security of Russian Federation]. Vestnik Volgogradskogo gosudarstvennogo universiteta. Seriya 4. Istoriya. Regionovedenie. Mezhdunarodnye otnosheniya [Bulletin of Volgograd State University. Series 4. History. Regional Studies. International Relationships], 2016, no. 3, pp. 122-131.

2. Gulyaikhin V.N., Andryushchenko O.E., Fantrov P.P. Tradicionnye duhovno-nravstvennye cennosti $\mathrm{v}$ associaciyah uchashchejsya molodezhi Volgogradskoj oblasti [Traditional Spiritual and Moral Values in the Associations of Student Youth of the Volgograd Region]. Sociologicheskie issledovaniya [Sociological Research], 2018, no. 11, pp. 146-151.

3. Muraev P.P. Vidy i zadachi zarubezhnyh i otechestvennyh podrazdelenij OVD po organizacii 
obespecheniya obshchestvennogo poryadka, ih vzaimodejstvie v preduprezhdenii prestuplenij [Types and Tasks of Foreign and Domestic Departments of the Internal Affairs Directorate for the Organization of Public Order, their Interaction in the Prevention of Crimes]. Vestnik Volgogradskoj akademii MVD Rossii [Bulletin of Volgograd Academy of Ministry of Internal Affairs of Russia], 2009, no. 3, pp. 102-109.

4. Muraev P.P., Yakovlev D.N., Shalimova V.V. Osobennosti profilaktiki ekstremizma v molodezhnoj srede [Features of the Prevention of Extremism in the Youth Environment]. Legal Concept $=$ Pravovaya paradigma, 2020, no. 2, pp. 43-49. DOI: https://doi. org/10.15688/lc.jvolsu.2020.2.6.

5. Muraev P.P., Solovyeva N.A. Pravovaya osnova deyatel'nosti operativnyh podrazdelenij organov vnutrennih del po vyyavleniyu, profilaktike $\mathrm{i}$ raskrytiyu prestuplenij, sovershaemyh organizovannymi prestupnymi formirovaniyami [Legal Basis for the Activities of Operational Units of the Internal Affairs Bodies to Identify, Prevent and Solve Crimes Committed by Organized Criminal Groups]. Vestnik Voronezhskogo instituta MVD Rossii [Bulletin of Voronezh Institute of Ministry of Internal Affairs of Russia], 2018, no. 3, pp. 147-152.

6. O koordinacii deyatel'nosti pravoohranitel'nyh organov po bor'be s prestupnost'yu: ukaz Prezidenta RF ot 18 aprelya 1996 g. № 567 (red. ot 31.12.2019) [On the Coordination of the Activities of Law Enforcement Agencies in the Fight Against Crime: Decree of the President of the Russian Federation № 567 of April 18, 1996 (as amended on 31.12.2019)]. Access from Reference Legal System “KonsultantPlyus”.

7. O sudebnoj praktike primeneniya zakonodatel'stva, reglamentiruyushchego osobennosti ugolovnoj otvetstvennosti i nakazaniya nesovershennoletnih: postanovlenie Plenuma Verhovnogo Suda Rossijskoj Federacii ot 1 fevralya 2011 goda [About Judicial Practice of Application of the Legislation Regulating Features of Criminal Responsibility and Punishment of Minors: The Resolution of the Plenum of the Supreme Court of the Russian Federation of February 1, 2011]. Ros. gaz., 2011, no. 29(5405).
8. Solovyova N.A., Fantrov P.P. Integraciya gosudarstva i grazhdanskogo obshchestva v sfere profilaktiki molodezhnogo ekstremizma v kontekste pravovoj socializacii [Integration of the State and Civil Society in the Field of Prevention of Youth Extremism in the Context of Legal Socialization]. Legal Concept $=$ Pravovaya paradigma, 2020, no. 2, pp. 21-26. DOI: https://doi.org/10.15688/lc.jvolsu.2020.2.3.

9. Fantrov P.P. Nacional'naya model' politicheskoj socializacii molodezhi i nacional'naya bezopasnost' Rossii [National Model of Political Socialization of Youth and National Security of Russia]. Nacional'nye interesy: prioritety $i$ bezopasnost' [National Interests: Priorities and Security], 2017, no. 2, pp. 261-269.

10. Shinkaruk V.M., Fantrov P.P. Koordinaciya deyatel'nosti pravoohranitel'nyh organov i konstruktivnyh associacij grazhdan v kontekste profilaktiki molodezhnogo ekstremizma [Coordination of the Activities of Law Enforcement Agencies and Constructive Associations of Citizens in the Context of the Prevention of Youth Extremism]. Voprosy rossijskogo i mezhdunarodnogo prava [Questions of Russian and International Law], 2020, № 7A, pp. 111-120.

11. Shinkaruk V.M., Fantrov P.P., Solovyova N.A. Protivodejstvie ekstremizmu v molodezhnoj srede: rol' prokurorskogo nadzora za ispolneniem zakonodatel'stva $\mathrm{v}$ dannoj sfere [Counteracting Extremism Among the Youth: The Role of Prosecutorial Supervision Over the Implementation of Legislation in this Area]. Vestnik Volgogradskoj akademii MVD Rossii [Bulletin of the Volgograd Academy of the Ministry of Internal Affairs of Russia], 2020, no. 4, pp. 178-188.

12. Shinkaruk V.M., Fantrov P.P. Setevye tekhnologii vzaimodejstviya silovyh i konstruktivnyh obshchestvennyh struktur v kontekste profilaktiki molodezhnogo ekstremizma [Network Technologies of Interaction Between Power and Constructive Social Structures in the Context of the Prevention of Youth Extremism]. Novye impul'sy razvitiya: voprosynauchnyh issledovanij: sb. st. Mezhdunar. nauch.-prakt. konf. [New Impulses for Development: Research Issues: Collection of Articles of the International Scientific and Practical Conference]. Saratov, KDU Publ., 2020, pp. 404-409. 


\section{Information About the Authors}

Pyotr P. Muraev, Candidate of Sciences (Jurisprudence), Associate Professor, Department of Criminal Procedure and Criminalistics, Volgograd State University, Prosp. Universitetsky, 100, 400062 Volgograd, Russian Federation, muraev@volsu.ru, https://orcid.org/0000-0002-9698-0845

Roman P. Muraev, Head of Department for the Detection of Serious and Especially Serious Crimes Against the Person of the Criminal Investigation Department, Department of the Ministry of Internal Affairs of Russia in Volgograd, Irkutskaya St, 20, 400074 Volgograd, Russian Federation, roman.muraev@inbox.ru, https://orcid.org/0000-0003-4361-067X

Olga E. Andryushchenko, Candidate of Sciences (Sociology), Associate Professor, Department of Criminal Procedure and Criminalistics, Volgograd State University, Prosp. Universitetsky, 100, 400062 Volgograd, Russian Federation, andryushchenko@volsu.ru, https://orcid.org/0000-0003-4619-160X

\section{Информация об авторах}

Петр Петрович Мураев, кандидат юридических наук, доцент кафедры уголовного процесса и криминалистики, Волгоградский государственный университет, просп. Университетский, 100, 400062 г. Волгоград, Российская Федерация, muraev@volsu.ru, https://orcid.org/0000-0002-9698-0845

Роман Петрович Мураев, начальник отделения по раскрытию тяжких и особо тяжких преступлений против личности отдела уголовного розыска, Управление МВД России по г. Волгограду, ул. Иркутская, 20, 400074 г. Волгоград, Российская Федерация, roman.muraev@inbox.ru, https://orcid.org/0000-0003-4361-067X

Ольга Евгеньевна Андрющенко, кандидат социологических наук, доцент кафедры уголовного процесса и криминалистики, Волгоградский государственный университет, просп. Университетский, 100, 400062 г. Волгоград, Российская Федерация, andryushchenko@volsu.ru, https://orcid.org/0000-0003-4619-160X 